\title{
Dispersion in Solute Transport Models: Concepts and Limitations in Simple Models
}

\author{
$\underline{\text { Freeman J Cook }}{ }^{\mathrm{a}}$ \\ ${ }^{a}$ Freeman Cook and Associates PTY LTD; The University of Queensland School of Food and Agriculture; \\ Griffith University School of Environment \\ Email:freeman@freemancook.com.au
}

\begin{abstract}
Dispersion occurs when solutes are transported in the atmosphere, porous media or waterways due to several processes. Dispersion smears out the concentration if a pulse input occurs on the inlet face of a domain as the solute is transported in the domain. This is due to a combination of molecular diffusion, due to the concentration gradient and fluid velocity differences occurring within the fluid. The effect of dispersion is critical when computing solute transport as the solute will arrive sooner than under purely advective (piston front) and although at a lower concentration may still be critical if a contaminant is above a threshold level.
\end{abstract}

Many models that describe solute transport use a simple box structure, with the spatial domain split into discrete volumes. The solute is then transported between the boxes using a transfer coefficient to account for both advection of the carrier fluid and dispersion. When both the time step and spatial discretization are small these models can approximate the differential equations of flow. However, when the time step and or spatial discretization is large they become models where dispersion is either added explicitly or implicitly as a consequence of the method of computation. In both cases it is worthwhile being able to determine how the method of computation affects dispersion in these models.

One method that is used with box models is to assume that all of the solute entering the box in the time step is fully mixed by the end of the time. This method is called a fully mixed tank reactor (FMTR). This method introduces dispersion purely by the method of computation, but this may be too little or too much dispersion. We consider a box model for a river or stream and use both the travel time of the water through the box and the Peclet number to consider their effect on the solute concentration at the outlet compared to an analytical solution of the transport.

Box models can trace a pulse of solute using advection and a fully mixed tank reactor (FMTR) model or by determining the centre of mass of the pulse. Here we compare how these different approaches will introduce errors in the

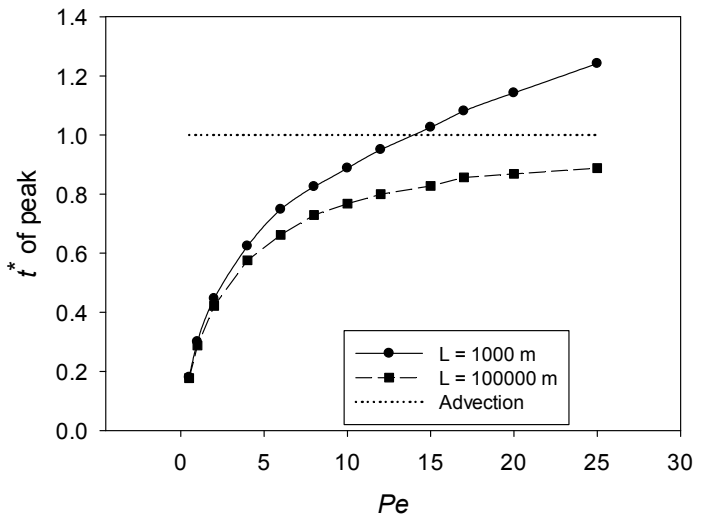

Figure 1. Dimensionless time $\left(t^{*}\right)$ at which the peak concentration is reached at $x=L$ for a pulse input at $x=0$ at $t=0$. Also shown is the time that a 'piston' or advective peck would arrive at $L$. concentration, related to the Peclet number of the flow, and show that if the true behaviour is to be approximated using a FMTR, the reach length or time step would have to vary with the flow velocity.

A purely advective approximation for determining the concentration center of mass can also fail as dispersion will move the centre of mass as well as advection. This can result in underestimation of concentration and arrival times of the peak concentration. Figure 1 shows the time of arrival at the outlet for a FMTR and piston flow methods.

Keywords: Dispersion, box models, solute transport 


\section{INTRODUCTION}

Box models are often used for modelling of flow in porous media (Neumann et al, 2011; Neuman et al. 2009), lakes (Sato and Schnoor, 1991) and rivers (Rauch, 1998). These models consist of segregating the spatial domain into boxes, where the state variables are usually constant for a set period of time. Fluxes of materials into and out of the boxes are then considered to be constant for a set period of time and the difference in the fluxes can then be used to update the state variables at the end of the time step. When the spatial and time steps are small such models approximate the differential equations that are often used to describe the flow of mass in the system domain (Neumann et al., 2011). When the spatial or temporal scale is large then the fluxes in the box models become transfer coefficients based on rules. The concentration of the state variable within the box can be calculated by a fully mixed approach (as in a fully mixed tank reactor (FMTR)). This can lead to numerical dispersion with the state variable (mass) moving too quickly downstream. Another approach is to estimate the position of the advective front within the box and then keep the concentration at its original value until the advective front reaches the end of the box and concentration changes as a square wave (Figure 2). These are the two end members of what is possible with many schemes for estimating the dispersion to include in the box models. Here I will consider a river model, the full differential equation description of river models is thoroughly reviewed by Cox (2003). A FMTR approximation of such a transport model is shown in figure 2.



Figure 2. Conceptualisation of box solute model for eWater Source model. The index variable $i$ is related to nodes and the index $j$ to time.

The flow of water in the box (reach) is described by flow rate from upstream $\left(Q_{i-1, j}\left(\mathrm{~m}^{3} \mathrm{~s}^{-1}\right)\right)$, input/output from the sub-catchment $\left(\Delta Q_{i, j}\left(\mathrm{~m}^{3} \mathrm{~s}^{-1}\right)\right)$ and outflow $\left(Q_{i, j}\left(\mathrm{~m}^{3} \mathrm{~s}^{-1}\right)\right)$, where the index variable $i$ is used for the spatial steps and the index variable $j$ is used for the temporal steps. The input/output from the sub-catchment includes such flows as runoff, groundwater flow, extractions and evaporation. These values are fixed at the start of the time step $(j)$ and generated by the hydrological component of the model. Associated with these water flows mass of solutes are inputted from upstream at the rate $m_{i-1, j}=Q_{i-1, j} c_{i-1, j}\left(\mathrm{~kg} \mathrm{~s}^{-1}\right)$ and within the box by $\Delta m_{i, j}$ $\left(\mathrm{kg} \mathrm{s}^{-1}\right)$ and outputted to the downstream box $m_{i, j}\left(\mathrm{~kg} \mathrm{~s}^{-1}\right)$. Mass of solute $\left(M r_{i, j}\left(\mathrm{~kg} \mathrm{~m}^{-1}\right)\right)$ per unit length of the box is stored within the water volume of the box $\left(V_{i, j}\right)$ of length $L_{i}(\mathrm{~m})$. The model is stepped forward in time as follows.

The storage of water in the box at the start of the next time step is given by:

$$
V_{i, j+1}=\left(Q_{i-1, j}-Q_{i, j}+\Delta Q_{i, j}\right) t_{s}+V_{i, j}
$$

where $t_{s}$ is the time step for the model (s). The travel time, $T_{i, j}(\mathrm{~s})$ for a parcel of water in the link is given by:

$$
T_{i, j}=A_{i, j} L_{j} / Q_{i, j}=L_{i} / V_{i, j}
$$


where $A_{i, j}$ is the mean cross-sectional area of the box $\left(\mathrm{m}^{2}\right)$ on that day, $v_{i, j}$ is the mean velocity in the link $\left(\mathrm{m} \mathrm{s}^{-}\right.$ ${ }^{1}$ ) and $L_{i}$ is the linear length of the box $(\mathrm{m})$. The travel time then determines what the concentration will be in the box at the next time step as:

$T<t_{s}$ the solute in the box at the start of the time step is displaced downstream along with the some of the input and plus or minus some additions or transformations within the box

$T=t_{s}$ the solute in the box at the start of the time step is displaced downstream plus or minus some additions or transformations within the box

$T>t_{s}$ some of the solute in the box at the start of the time step is displaced downstream plus or minus some additions or transformations within the box.

\subsection{Definition of the Problem}

It is the latter condition that results in dispersion and is the one of interest here. If we ignore the additions and transformations that may occur in the box i.e. the only input is from the upstream box then we can derive the concentration at the downstream end of the box as:

$$
\begin{gathered}
M r_{i, j+1}=m_{i-1, j} t_{s} / L_{i}+M r_{i, j}\left(L_{i}-t_{s} Q_{i-1, j} / A_{i, j}\right) \\
m_{i, j}=M r_{i, j} Q_{i, j} / A_{i, j}
\end{gathered}
$$

The differential equation for this problem is described by:

$$
\frac{\partial c}{\partial t}=D \frac{\partial c}{\partial x}-v \frac{\partial c}{\partial x}
$$

where $D$ is the dispersion coefficient $\left(\mathrm{m}^{2} \mathrm{~s}^{-1}\right)$ and $v=Q / A$ is the average advective velocity of the fluid $\left(\mathrm{m} \mathrm{s}^{-1}\right)$. For a pulse input of time length $t_{0}$ with the pulse concentration $c_{f}\left(\mathrm{~kg} \mathrm{~m}^{-3}\right)$ and a length of box of $L(\mathrm{~m})$ the initial and boundary conditions are:

$$
\begin{aligned}
& c_{0}(x, t)=0, \quad t=0, \quad 0 \leq x \leq L \\
& c(0, t)=c_{f}^{*}=c_{f}-\left.\frac{D Q}{A} \frac{d c}{d x}\right|_{x=0}, 0<t \leq t_{0} \\
& D \frac{d c}{d t}=0, \quad x=L
\end{aligned}
$$

An analytical solution exists for (4) subject to these initial boundary conditions for a pulse and for the concentration at $L\left(c_{e}\right)$ is (Brenner, 1962):

$$
c^{*}\left(x=L, t^{*}\right)=2 \exp \left[P\left(2-t^{*}\right)\right] \sum_{k=1}^{\infty} \frac{\lambda_{k} \sin \left(2 \lambda_{k}\right) \exp \left(-\lambda_{k}^{2} t^{*} / P\right)}{\lambda_{k}^{2}+P^{2}+P}
$$

where $c^{*}=\left(c_{e}-c_{0}\right) /\left(c_{f}-c_{0}\right), P=P_{e} / 4=v L / 4 D, P_{e}$ is the Peclet number, $t^{*}=t v / L=t / T$ and $\lambda_{k}$ are the positive roots taken in order of increasing magnitude of $\tan (2 \lambda)=2 \lambda P /\left(\lambda^{2}-P^{2}\right)$. This solution breaks down at small values of $t$ and large values of $P$ and then an asymptotic solution is required (Brenner, 1962):

$$
\begin{aligned}
c^{*}(x & \left.=L, t^{*}\right)=1-\frac{\operatorname{erfc}\left[\left(1-t^{*}\right) \sqrt{P / t^{*}}\right]}{2}-\left[3+2 P\left(1+t^{*}\right)\right] \exp \left[\frac{-P\left(1-t^{*}\right)^{2}}{t^{*}}\right] \sqrt{\frac{4 P t^{*}}{\pi}} \\
& +\left[1 / 2+2 P\left(3+4 t^{*}\right)+4 P^{2}\left(1+t^{*}\right)^{2}\right] \exp (4 P) \operatorname{erfc}\left[\left(1+t^{*}\right) \sqrt{P / t^{*}}\right]
\end{aligned}
$$

The range where either (5) or (6) is appropriate is given in Brenner (1962, Fig. 1). 
Freeman J Cook, Dispersion in Solute Transport Models: Concepts and Limitations in Simple Models.

\section{METHODS}

For the FMTR for a single box with the pulse input as given above it can be shown that the concentration at the outlet is given by a geometric series:

$$
\begin{aligned}
& c_{e}\left(t^{\prime}=1\right)=c_{0} \\
& c_{e}\left(t^{\prime}\right)=c_{0}+\left(c_{f}-c_{0}\right) \tau(1-\tau)^{t^{\prime}-2}, \quad t^{\prime}=t / t_{s}, \quad t^{\prime} \in I
\end{aligned}
$$

where $\tau=t_{s} / T$ is the dimensionless time step relative to the travel time and $t$ is the number of time steps since the pulse started. A similar geometric series can be derived for a continuous step change in concentration but is not presented here.

A program in Matlab was written to solve (5), (6) and (7) and the results were computed for a range of Peclet numbers from 2 to 30 and range of lengths from 1000 to $100,000 \mathrm{~m}$. The dispersion coefficient was taken as $0.28 \mathrm{~m}^{2} \mathrm{~s}^{-1}$ from Kim et al. (2011). The travel times and velocities computed for this range are given in Table 1.c

Table 1. Values of $P e$ and $L$ used in the calculations and values of $v$ and $T$ calculated from these with $D=0.28$

\begin{tabular}{|c|c|c|c|c|c|c|c|c|c|c|}
\hline \multirow[t]{2}{*}{$P e$} & \multicolumn{2}{|c|}{$L=1000 \mathrm{~m}$} & \multicolumn{2}{|c|}{$L=5000 \mathrm{~m}$} & \multicolumn{2}{|c|}{$L=10000 \mathrm{~m}$} & \multicolumn{2}{|c|}{$L=50000 \mathrm{~m}$} & \multicolumn{2}{|c|}{$L=100000 \mathrm{~m}$} \\
\hline & $\begin{array}{l}v \\
\left(m \text { day }^{-1}\right)\end{array}$ & $\begin{array}{l}\mathrm{T} \\
\text { (day) }\end{array}$ & $\begin{array}{l}v \\
\left(\mathrm{~m} \text { day }{ }^{-1}\right)\end{array}$ & $\begin{array}{l}T \\
\text { (day) }\end{array}$ & $\begin{array}{l}v \\
\left(m \text { day }^{-1}\right)\end{array}$ & $\begin{array}{l}\mathrm{T} \\
\text { (day) }\end{array}$ & $\begin{array}{l}V \\
\left(\mathrm{~m} \text { day }{ }^{-1}\right)\end{array}$ & & $\begin{array}{l}V \\
\left(\mathrm{~m} \text { day }^{-1}\right)\end{array}$ & $\begin{array}{l}T \\
\text { (day) }\end{array}$ \\
\hline 0.5 & 12 & 83.33 & 2.4 & 2083 & 1.2 & 8333 & 0.24 & 208333 & 0.12 & 833333 \\
\hline 1 & 24 & 41.67 & 4.8 & 1042 & 2.4 & 4167 & 0.48 & 104167 & 0.24 & 416667 \\
\hline 2 & 48 & 20.83 & 9.6 & 520.8 & 4.8 & 2083 & 0.96 & 52083 & 0.48 & 208333 \\
\hline 4 & 96 & 10.42 & 19.2 & 260.4 & 9.6 & 1042 & 1.92 & 26042 & 0.96 & 104166 \\
\hline 6 & 144 & 6.94 & 28.8 & 173.6 & 1.44 & 694.4 & 2.88 & 17361 & 1.44 & 69444 \\
\hline 8 & 192 & 5.21 & 38.4 & 130.2 & 1.92 & 520.8 & 3.84 & 13021 & 1.92 & 52083 \\
\hline 10 & 240 & 4.17 & 48.0 & 104.2 & 2.4 & 416.7 & 4.8 & 10417 & 2.40 & 41667 \\
\hline 15 & 360 & 2.78 & 72.0 & 69.4 & 3.6 & 277.8 & 7.2 & 6944 & 3.60 & 27778 \\
\hline 20 & 480 & 2.08 & 96.0 & 52.1 & 4.8 & 208.3 & 9.6 & 5208 & 4.80 & 20833 \\
\hline 25 & 600 & 1.67 & 120 & 41.7 & 6.0 & 166.7 & 12.0 & 4167 & 6.00 & 16667 \\
\hline 30 & 720 & 1.39 & 144 & 34.7 & 7.2 & 138.9 & 14.4 & 3472 & 7.20 & 13889 \\
\hline
\end{tabular}
$\mathrm{m}^{2} \mathrm{~s}^{-1}$. Note for convenience the time and velocity are in units of day and $\mathrm{m}^{-1 a y^{-1}}$ respectively.

\section{RESULTS AND DISCUSSION}

The time step $\left(t_{s}\right)$ was fixed at $86400 \mathrm{~s}$ ( 1 day) in the results shown and the other parameters varied. The pulse time length was taken as one time step i.e. $t_{0}=t_{s}$. The value of $c_{0}$ and $c_{f}$ were taken as 0 and $1 \mathrm{~kg} \mathrm{~m}^{-3}$ respectively so maximum possible value for $c_{e}$ is $1 \mathrm{~kg} \mathrm{~m}^{-3}$. The FMTR model results in increase dispersion of the concentration (smearing out) as the value of $\tau\left(=t_{s} / T\right.$, time step/travel time) decreases (fig. 3$)$. The other feature of this result is that it shows that the maximum concentration always occurs at $t^{*}=2$. The fully mixed condition will always give this result which offers a means to estimate the box length required so the peak occurs at $t^{*}=$ 2. A value of $t^{*}=2$ implies that $T=2 t_{s}$ and using the definitions of $T$ and $P_{e}$ we can rearrange to get a value for $L$ when $t^{*}=2$ given by:

$$
L_{p}=\sqrt{P_{e} D t_{s}}
$$


Thus, if an FMTR model had box lengths around $L_{p}$ this would mean that the model would, at least estimate the peak concentration at the correct time. However, (8) will have to be solved recursively as $L$ occurs in the $P_{e}$ term.

The length of the box has an effect on the peak concentration but little effect on the position of the dimensionless time $\mathrm{t}^{*}$ at which the peak occurs when the value of $P_{e}$ was a constant value of 2 (Fig. 4). The peak position predicted with the analytical solution is at approximately $t^{*}=0.4$. Given that $D$ is taken as a constant, then as $L$ increases the velocity will have to decrease for $t^{*}$ to be constant. From the values in Table 1 and the definition of $t^{*}$ we can calculate the time which the peak occurred with the analytical solution which is $8.3,208,833$ and 20833 days for $L$ of $1000,5000,10000$ and $50000 \mathrm{~m}$ respectively. As the box size gets longer

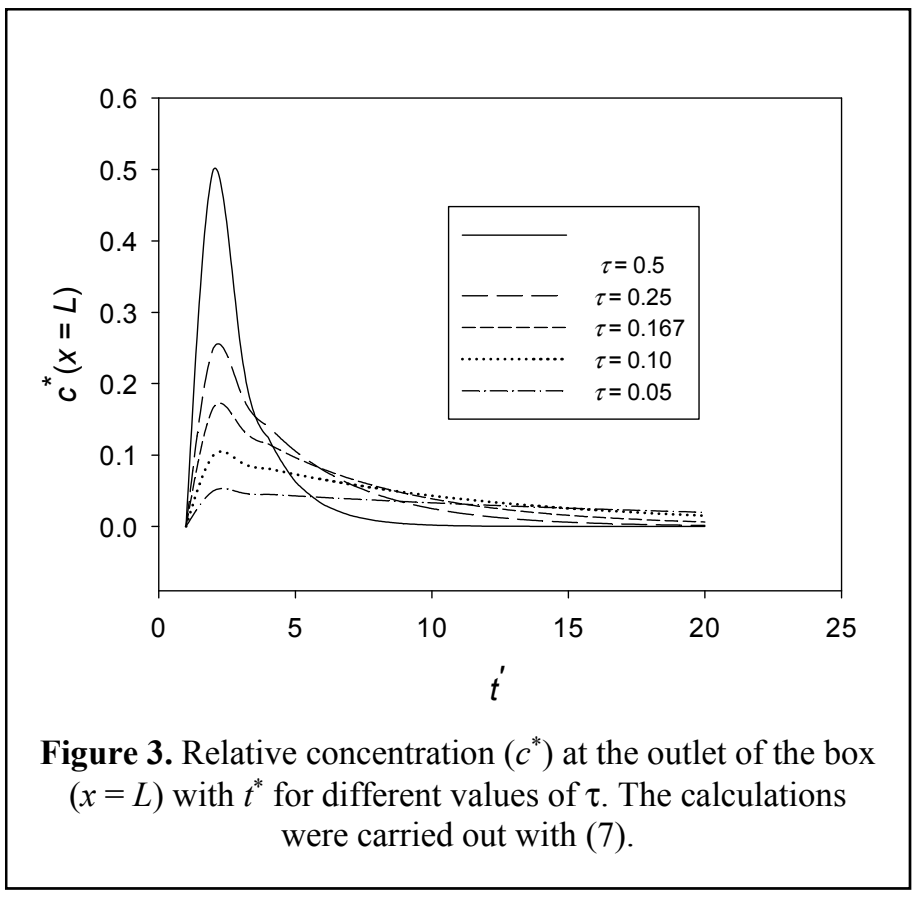
the discrepancy between the peak time for the FMTR of 2 days and the analytical solution gets larger. From (8) we can calculate the desired box length for the peak to occur at 2 days and this is $220 \mathrm{~m}$. The results in figure 3 also show that the concentration is too high at $t^{*}<0.2$ and too low for $t^{*} \geq 0.2$.

For a fixed $L=$ $1000 \mathrm{~m}$ the results show that as the $P_{e}$ increases to about 20 the FMTR model will get closer at predicting the peak time (Table 1), as $T$ is

approximately 2 . The velocity will need to be high at $480 \mathrm{~m}$ per day which is moderate. At higher velocities $T$ will decrease to less than 2 .

If, as is used in some models, a fixed time step is used then this will mean that the length of the boxes will need to be carefully consider if the

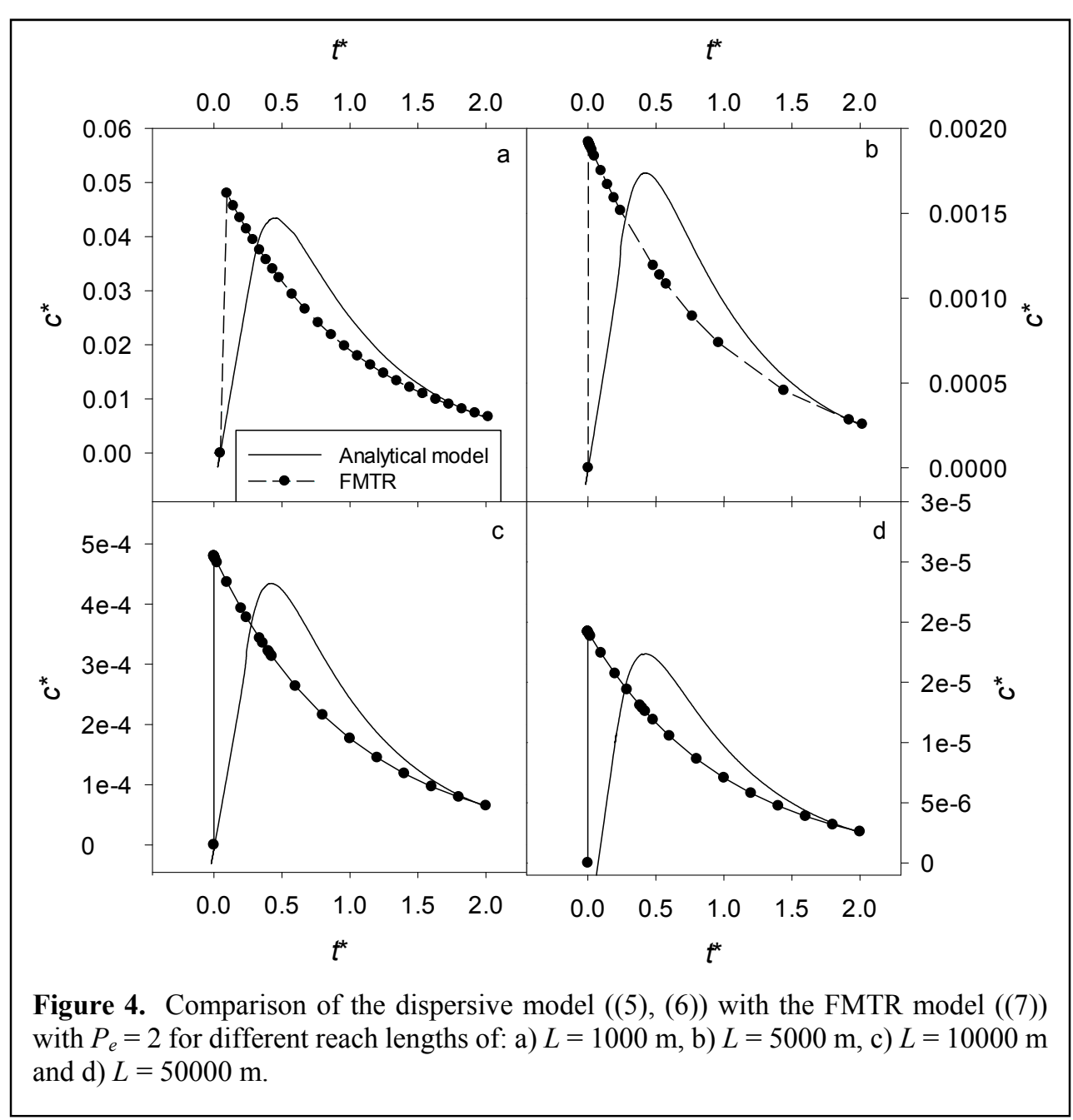


FMTR method is used. Taking a fixed $t_{s}$ of 1 day and a range of $D$ from 0.01 to $1 \mathrm{~m}^{2} \mathrm{~s}^{-1}$ along with values of $P_{e}$ from 0.5 to 50 the range of values of $L$ can be calculated with (8) (Fig. 5). These values of $D$ are in the range of values measured in Australian rivers: 0.04 to $0.15 \mathrm{~m}^{2} \mathrm{~s}^{-1}$ in Magela Creek (Airey et al., 1984); 0.11 to $0.12 \mathrm{~m}^{2} \mathrm{~s}^{-1}$ in the Torrens River (Jones, 2005).

An alternative simple solute transport model is to use the travel time (advective model) and calculate the center of mass of the solute plume and distribute the mass with leading and trailing shape factor (Close, 1996; Cook and Bartley, 2009). The problem with this modelling approach is that the center of mass position is also affected by dispersion. This is especially true if the box (reach) length is long and the $P_{e}$ low. For example, for a length of $100 \mathrm{~km}$ and $P$ e of 2 the analytical model would predict the peak to reach the exit at 88000 days while the advective nodel would predict 208333 days. However, this would represent a very low flow velocity of $0.48 \mathrm{~m} \mathrm{day}^{-1}$. Whereas if $L=1 \mathrm{~km}$ and $P_{e}=30$ then the velocity will be $720 \mathrm{~m}_{\text {day }}{ }^{-1}$ and advective model will estimate a peak at 1.4 days and the analytical model 1.8 days (Figure 1). The advective and FMTR models will give best estimates when $T=2 t_{s}$. When $T>2 t_{s}$ the FMTR underestimate while the advective model will overestimate the peak arrival time at the exit from the box.

Figure 6 shows the relationship between the peak concentration value and the Peclet number for the three different models and two values of $L$. We have assumed that for the advective model the peak concentration will remain at the inlet concentration. The peak concentration is similar for the FMTR and analytical solution models up to a $P_{e}$ of about 10. The peak concentration for the FMTR then underestimates compared to the analytical solution, while the advective model overestimates throughout range of $P_{e}$ values. What all of these results show is that for the FMTR model to give reasonable estimates of solute transport in box models the length of the box and/or the time steps need to be appropriate. Often such models use a fixed time step, so it is the length of the box that is the only variable that can be changed.

The results presented here indicate how box models used in many of the fields of application: atmosphere, rivers, lakes oceans; porous media, can be properly designed so that the numerical dispersion is similar to the actual dispersion. What this shows is that where fixed time steps are used and the range of velocities and hence Peclet numbers vary the length of the box will either need to vary or in interpreting the results the user will need to consider the fact that the model may over- or underestimate the dispersion. The problems with these simple box models has led to the development of models using moments to better estimate the dispersion in fluid transport models (Adams et al., 1992; Zhang et al., 2008). 
Freeman J Cook, Dispersion in Solute Transport Models: Concepts and Limitations in Simple Models.

\section{CONCLUSION}

A geometric series is developed for the exit concentration foe box models based on the fully mixed tank reactor (FMTR) approach. This is used along with an analytical solution of solute transport in the box for a pulse input to show that the FMTR will only be approximately correct when the travel time of fluid in the box is equal to two time steps.

An approximate solution for determining the appropriate box length is developed and it shows that for river models the value could vary up to $2000 \mathrm{~m}$ depending on the $P_{e} D$ (fig. 5).

Purely advective solutions are also compared to the analytical solution and shown to only give a good approximation of the peak exit concentration when $P_{e}$ is large.

\section{REFERENCES}

Adams, E.E. and Gelhar, L.W. (1992). Field study of dispersion in a heterogeneous aquifer: 2. Spatial moments analysis. Water Resources Research 28(12), 3293-3307.

Airey, P.L., Calf, G.E., Davison, A., Easey, J.F. and Morley, A.W. (1984). An evaluationof tracer dilution techniques for gauging rivers in flood. Journal of Hydrology, 74, 105-118.

Brenner, H. (1962). The diffusion of longitudinal mixing in beds of finite length. Numerical values. Chemical Engineering Science, 17, 229-243.

Close, A. (1996). A new daily model of flow and solute transport in the River Murray. 23 ${ }^{\text {rd }}$ Hydrology and Water Resources Symposium, Hobart, Australia, 21-24 May 1996, 173-178.

Cook, F.J. and Bartley, R (2011). Review of modelling of constituent transport in catchments and comparison of model frameworks in eWater SOURCE. eWater CRC, 29p.

Cox, B.A. (2003). A review of currently available in-stream water quality models and their applicability for simulating dissolved oxygen in lowland rivers. The Science of the Total Environment, 314, 335-377.

Jones, R. (2005) Mixing and Dispersion in Adelaide Coastal Waters. Honours thesis, University of Western Australis, 182pp.

Kim, K-C., Park, G-H., Jung, S-H., Lee, J-L. and Suh, K-S. (2011). Analysis on the characteristics of a pollutant dispersion in river environment. Annals of Nuclear Energy, 38, 232-237.

Neumann, L.N., Cook, F., Western, A.W. and Verburg, K. (2009). A one-dimensional solute transport model for hydrological response units. 18 ${ }^{\text {th }}$ World IMACS Congress and MODSIM 2009 International Congress on Modelling and Simulation, Cairns, Australia, July 13-17, 3528-3534.

Neumann, L.N., Simunek, J. and Cook, F.J. (2011). Implementation of quadratic upstream interpolation schemes for solute transport into HYDRUS-1D. Environmental Modelling and Software, 26, 1298-1308.

Rauch, W., Henze, M., Koncsos, L., Reichert, P., Shanahan, P., Somlyody, L. and Vanrolleghem, P. (1998). River water quality modelling: I. State of the art. Water Science and Technology, 38, 237-244.

Sato, C. and Schnoor, J.L. (1991). Applications of three completely mixed compartment models to the longterm fate of dieldrin in a reservoir. Water Research, 25, 621-631.

Zhang, Y., Benson D.A. and Baeumer, B. (2008). Moment analysis for spatiotemporal fractional dispersion. Water Resources Research 44(4) DOI: 10.1029/2007WR006291. 